\title{
CENTRALIDADE E IMATERIALIDADE DO TRABALHO: CLASSES SOCIAIS E LUTA POLÍTICA
}

\author{
CENTRALITY AND IMMATERIALITY OF LABOR: SOCIAL CLASSES AND POLITICAL STRUGGLE
}

Henrique Amorim ${ }^{1}$

Resumo Os debates sociológicos, surgidos nos anos 1970 e nas décadas seguintes, que se estruturam em resposta à suposta crise do marxismo, partem de um pressuposto comum, a saber, a ineficácia da teoria marxista e de suas categorias analíticas fundamentais para compreender a realidade heterogênea das sociedades contemporâneas. O diagnóstico é simples: os conceitos de classe social, trabalho e luta de classes não dariam mais conta da dinâmica social de final do século XX e início do XXI. O objetivo central dessa perspectiva, no entanto, concentra-se não em localizar o problema, mas em generalizá-lo a toda bibliografia marxista. Se, por um lado, a crítica às concepções de classe social, de trabalho e de luta política restrita à fábrica é fundamental, por outro, não pode ser considerada como momento de superação da problemática teórica marxista. Neste ensaio, tenho a intenção de explicitar o ponto de partida e os limites das teses sobre a não centralidade do trabalho e sobre o trabalho imaterial como força produtiva central na medida em que farei uma leitura das classes sociais, do trabalho e da luta política diferente daquela criticada pelas teses que compõem esses debates.

Palavras-chave centralidade e imaterialidade do trabalho; classe social; luta política e marxismo.
Abstract The sociological debates that arose in the 1970s and in the following decades, structured in response to the perceived crisis of Marxism, are based on a common assumption, namely, the ineffectiveness of Marxist theory and of its fundamental analytical categories to understand the heterogeneous reality of the contemporary societies. The diagnosis is simple: the social class, labor, and class struggle concepts could no longer stand up to the social dynamics of the late 20 th and early 21 st centuries. The main objective of this perspective, however, focuses not on finding the problem, rather on generalizing it to the entire Marxist literature. If, on one hand, the criticism of the notions of social class, labor, and political struggle limited to the factory is fundamental, on the other, it cannot be regarded as a moment of overcoming the Marxist theoretical problem. In this essay, I intend to clarify the starting point and the boundaries of the theories about the non-centrality of labor and about immaterial labor as a central productive force in which I will make a reading of social classes, labor, and of the political struggle unlike that which is criticized by the theses that make up these debates.

Keywords centrality and immateriality of labor; social class; political struggle and Marxism. 
O debate sobre a centralidade e não centralidade do trabalho, seguido pelo debate sobre o trabalho imaterial, surgidos, respectivamente, nos anos 1980 e 1990, pertencem, em conjunto, a uma mesma problemática teórica. Podese dizer que um é extensão do outro, já que se prestam ao rechaço teórico (debate sobre a centralidade do trabalho) e de atualização (debate sobre o trabalho imaterial) do marxismo. Aparentemente, são debates que se apresentam de modo teoricamente distinto. No entanto, referem-se a uma concepção de trabalho, de classe social e de luta política comuns: àquela desenvolvida e divulgada pelos partidos comunistas na Europa sob influência do partido comunista soviético.

Nesses termos, quando indico tal concepção de trabalho, de classe trabalhadora e de luta política, me refiro ao trabalho restrito à indústria, por isso, produtivo ao capital e que qualifica os trabalhadores ali existentes, somente eles, a potencialmente revolucionários.

Esse universo produtivo e de luta política foi, durante a maior parte do século XX, eleito como espaço central das lutas sociais anticapitalistas. Nesse sentido, toda e qualquer mudança fora desse universo foi considerada reformista. Se o sujeito revolucionário já tinha sido marcado com ferro, a única alternativa à teoria social seria capacitá-lo, garantir sua maturação, indicando a melhor estratégia revolucionária.

Em termos abrangentes, essa estratégia política tinha como antessala a retomada do controle dos processos de trabalho. Voltar a dominar o trabalho para depois atingir o Estado, tomá-lo. A luta, porém, teria percalços. O operário encontrava-se alienado tanto do processo quanto do produto do trabalho. A alternativa estaria em um processo de desalienação, em um reencontro com o trabalhador de ofícios, aquele que conservava o seu saber-fazer. ${ }^{2}$

Portanto, tanto a discussão sobre a centralidade do trabalho quanto a discussão sobre o trabalho imaterial trazem consigo a influência dessa concepção de trabalho, classe social e luta política. No primeiro debate, o objetivo é romper com ela, haja vista que a alternativa anticapitalista não estaria mais na fábrica, a revolução não viria mais da fábrica e o capitalismo teria aprendido a viver com suas próprias contradições sociais. Na segunda, sob insistente reprodução e ampliação das formas de exploração e dominação na produção de mercadorias, o trabalho e o valor são retomados como temas sociológicos. No entanto, algo ainda deveria ser descartado. A teoria do valortrabalho é colocada em xeque, o trabalho imaterial surge, então, como forma tendencialmente predominante de produção. Sua existência implicaria, portanto, na própria superação do capital como relação social hegemônica no capitalismo.

A discussão que realizo neste ensaio tem a intenção de mapear criticamente esses debates na medida em que, ao explicitar as bases teóricas que os orientam, apresenta uma leitura distinta sobre o trabalho, as classes 
sociais e a luta política. Para tal, a discussão será encaminhada com base nas análises de André Gorz, autor representativo desse movimento de abandono das categorias de análise marxistas e, posteriormente, de sua retomada, mesmo que sob novos moldes. Nesse sentido, a obra de Gorz se apresenta de forma emblemática para a análise e crítica dessa discussão. Não obstante, autores como Claus Offe e Antonio Negri também serão importantes para a construção de nosso argumento no sentido em que suas teses se assemelham às de Gorz.

\section{O debate sobre a centralidade do trabalho}

A conjuntura na qual surge o debate sobre a centralidade do trabalho foi marcada pela ascensão do neoliberalismo de Margaret Thatcher, na Inglaterra, em 1979, e de Ronald Reagan, nos Estados Unidos, em 1981, pela desestruturação política e econômica da União Soviética e pela ofensiva do capital ativada pela reestruturação produtiva.

Nesse momento, muitos autores do 'mundo do trabalho' reviram seus pressupostos analíticos no que concerne às transformações dos processos de trabalho, do movimento operário e da classe trabalhadora frente a uma virtual crise do trabalho.

A revisão chegou, então, ao chamado paradigma produtivo e às aspirações revolucionárias do operariado ali envolvido. Desenvolveu-se, com isso, durante as décadas de 1980 e 1990, um leque de teorias que tiveram por objetivo 1) negar a centralidade do trabalho, 2) invalidando a análise marxista.

Frente à redução da dimensão do operariado industrial e à diminuição das taxas de sindicalização e do ativismo sindical, a centralidade do trabalho foi posta em xeque. Com as metamorfoses nos processos de trabalho, a classe trabalhadora teria se tornado fragmentada e heterogênea.

Offe (1989), por exemplo, notou um deslocamento do número de postos de trabalho da indústria para o setor de serviços, o que implicaria uma nova forma de organização política, fora da indústria. A política, antes restrita ao universo da produção, se deslocaria para fora dos "laços do trabalho", para fora da fábrica, já que a diminuição de operários havia causado a perda de poder do operariado industrial.

A sociedade civil passou, dessa forma, a ser considerada como o grande cenário de luta política. Nela, os movimentos sociais passariam a desempenhar o papel que outrora teve como protagonista o operariado tradicional na indústria (Gorz, 1987; 1991). Questões vinculadas ao status familiar, ao gênero, saúde, idade, etnia e processos identitários cresciam em importância no seio da sociedade civil. Portanto, a categoria trabalho parecia ter perdido teoricamente sua centralidade. 
Uma das críticas possíveis a esta perspectiva seria a de que estas análises estão marcadas por uma articulação mecânica entre a redução do número de operários presentes na indústria e a forma e a capacidade de organização de sua resistência. No entanto, podemos lembrar ainda que tais perspectivas fundamentaram uma definição da classe operária restrita à produção industrial.

Assim, a defensiva da classe trabalhadora apresentada no debate sobre a centralidade do trabalho seria caracterizada a partir do número de trabalhadores ligados a um dado setor dentro da estrutura ocupacional (industrial). Dessa forma, pressupostos de caráter quantitativo sobre o processo de organização da classe trabalhadora limitariam a possibilidade de tratar qualitativamente as modalidades emergentes de mobilização e organização classista. Nesses termos, a possibilidade de atualização dos conflitos e dos antagonismos sociais, dentro de uma perspectiva de classe, foi rejeitada.

Adeus ao proletariado: para além do socialismo, de André Gorz (1987), é o livro que dá início ao debate sobre a centralidade e não centralidade do trabalho. Gorz parte da seguinte afirmação: a crise do proletariado e a crise do marxismo associam-se. As mutações da classe operária fundamentariam a própria crise do marxismo (Gorz, 1987, p. 85). Ademais, a sociedade capitalista resistiria e o desenvolvimento das forças produtivas, compatível com as formas de exploração e dominação capitalistas, seria o sinal da prevalência das formas de produção capitalistas e da insuperável alienação no trabalho.

Gorz desenvolve seu raciocínio da seguinte forma: a contradição entre um proletariado estraçalhado pelo trabalho excessivamente racionalizado e sua disposição emancipadora acabaria por condicioná-lo a uma impotência intransponível. O capitalismo produziu uma classe operária que, em sua maior parte, não tem capacidade para ser proprietária ou gestora dos meios de produção. Dessa forma, uma possível confrontação classista acerca do ideal de vida burguês repousaria em camadas que viessem a constituir uma 'racionalidade diferente', uma camada que encamparia como finalidade básica a dissolução de todas as classes sociais.

Gorz estrutura seu discurso com base em três argumentos. Primeiro, o de que a alienação do trabalhador em relação ao seu trabalho seria insuperável. Assim,

A única chance de abolir as relações de dominação é reconhecer que o poder funcional (poder alienado) é inevitável e conceder-lhe um lugar circunscrito, determinado de antemão, de maneira a dissociar o poder e dominação e a proteger as autonomias respectivas da sociedade civil, da sociedade política e do Estado (Gorz, 1987, p. 81).

Em seu segundo argumento, o indivíduo, às custas dessa insuperável alienação, jamais se reconheceria como parte do coletivo, já que sua repre- 
sentação política seria garantida pelo Estado. A conquista do poder pelo proletariado teria um caráter apenas substitutivo, já que o poder a ser conquistado seria apenas transferido de mãos, subsistindo a impessoalidade e o caráter burocrático do Estado.

O terceiro argumento concentra-se na designação de que "o proletariado é constitutivamente incapaz de se tornar sujeito do poder" (Gorz, 1987, p. 80). Essa incapacidade teria sido imposta pela burguesia com base na incorporação de processos de trabalho (taylorismo e fordismo) que eliminaram do trabalho sua dimensão criativa e as possibilidades de identificação do operário com seu trabalho (Gorz, 1987, p. 58).

Gorz parece se remeter aqui à figura do trabalhador de ofício como um tipo ideal. Traçando um corte distintivo entre este trabalhador e o 'póstaylorista', o autor sugere que o primeiro tinha como objetivo estrutural a tomada do Estado. Como uma massa homogênea de trabalhadores com tradições e organizações inclinadas a estabelecer uma cultura diametralmente oposta à burguesa, tinha condição de atingir tal objetivo político. Já o segundo, sendo uma camada "miserável, oprimida, ignorante, desenraizada", estaria incapacitado de tomar o Estado (Gorz, 1987, p. 59).

A retomada teórica do trabalhador de ofício não é gratuita. Gorz traz ao debate a afirmação de que o último sujeito possível da revolução socialista, pautado na teoria do valor, deveria ser aquele que reconquistasse, sob a insígnia da politecnia, seu saber-fazer. No entanto, a reestruturação produtiva aniquilou esse tipo de trabalhador.

Com o desaparecimento do operário profissional polivalente, sujeito possível de seu trabalho produtivo e, portanto, sujeito possível da transformação revolucionária das relações sociais, desapareceu a classe capaz de tomar sob sua responsabilidade o projeto socialista e de realizá-lo nas coisas. A degenerescência da teoria e da prática socialistas vem fundamentalmente disso (Gorz, 1987, p. 85).

A única possibilidade de superação política da sociedade capitalista seria alcançada, nestes termos, pela formação de um novo sujeito histórico, um sujeito descolado da produção alienada, um sujeito situado para além das fábricas. Esse novo sujeito viria exatamente do oposto simétrico do operariado, isto é, de um grupo desprendido das formas de dominação produtivas que reproduziriam sua hegemonia de classe. O gérmen de uma nova cultura residiria no oposto absoluto da classe trabalhadora, a saber, na "nãoclasse" dos "não-trabalhadores" (Gorz, 1987, p. 17-19).

A "não-classe" seria formada a partir de uma imposição conjuntural que diluiria o operariado tradicional na tentativa de reproduzir as relações sociais burguesas. Ou seja, caracterizou-se uma necessidade histórica natural de transformação das chamadas formas de resistência política. Valeria, então, 
antecipar a esse movimento inevitável de dissolução da classe trabalhadora, engrossando a ideia de que o trabalho não desempenharia mais um papel central na constituição das lutas políticas frente à racionalidade capitalista.

Nesse sentido, apenas os indivíduos fora desse tipo de atividade alienada e impessoal seriam capazes de criar uma "nova identidade", "um pertencimento de classe" que instaurasse a transformação da estrutura social capitalista, condicionando-a a seu apêndice (Gorz, 1987, p. 85-93).

Surge, assim, a figura de um 'não-sujeito' como forma negativa do trabalho: 'a não-classe dos não-trabalhadores', que se tornaria a forma iminente e tendencial de uma possível liberação do trabalhador.

Essa não-classe engloba, na realidade, o conjunto dos indivíduos que se encontram expulsos da produção pelo processo de abolição do trabalho, ou subempregados em suas capacidades pela industrialização (ou seja, pela automatização e pela informatização) do trabalho intelectual (Gorz, 1987, p. 88).

Diferente daquele operário polivalente que fundamentava seu poder político-reivindicativo em um conhecimento técnico da produção, o 'proletariado pós-industrial' legitimaria sua força em sua própria marginalidade. Nesse sentido, Gorz parece indicar a formação de uma contracultura, determinada pelas relações sociais daqueles despossuídos de qualquer vínculo com a "produção de necessidades", um "modo de vida" de "não-trabalhadores anticapitalistas".

Diferentemente da classe operária tradicional, essa não-classe é subjetividade liberada. Enquanto o proletariado industrial tirava da transformação da matéria um poder objetivo que levava a se considerar como uma força material, base de todo o devir social, o novo proletariado é não-força, desprovido de importância social objetiva, excluído da sociedade (Gorz, 1987, p. 92).

O tempo liberado torna-se, com isso, eixo teórico central para a análise da luta política para além das organizações sindicais e partidárias restritas às fábricas e à racionalidade capitalista alienante. Nesse momento, a referência aos Grundrisse de Marx é explicitada. Segundo Gorz, Marx indicaria o aparecimento de um tempo que seria liberado pelo desenvolvimento das forças produtivas; tempo que poderia ser usufruído de maneira autônoma, desvinculada da economia burguesa e da alienação por ela imposta.

Gorz realiza uma leitura determinista de Marx. O desenvolvimento das forças produtivas teria criado um novo cenário político onde o tempo de não trabalho deveria ser preenchido pela luta política.

Não obstante, a sociedade atual ainda está baseada no tempo de trabalho vivo, ou seja, ainda tem como medida do valor o tempo de trabalho na 
produção imediata. Este tempo de trabalho necessário, agora diminuído, não tem como finalidade própria permitir à maioria dos homens e mulheres, liberados da produção, dispor livremente do tempo crescente de não-trabalho (Tosel, 1995). A economia capitalista funciona, dessa forma, com base no desperdício de recursos humanos e na marginalização de uma parte crescente da força de trabalho.

(...) a centralidade do trabalho abstrato produz a não-centralidade do trabalho na massa dos excluídos do trabalho vivo, de todos aqueles que não podem mais (se fazer) aparecer como individualizados e socializados pelo trabalho, e que buscam desesperadamente formas de individuação e de socialização nas únicas esferas do nãotrabalho (atividades de formação, de benevolato e de serviços) (Tosel, 1994, p. 210).

Portanto, a centralidade atual do não-trabalho é negativa, pois não permite a organização relacional entre atividades inseridas no tempo de trabalho e atividades inseridas no tempo liberado. Esse tempo livre, indicado por Gorz como uma tendência a ser explorada, não permitiria o desenvolvimento integral das capacidades humanas, pois ele é negativamente liberado pela forma do desemprego, vinculando, assim, a impossibilidade material de sua fruição (Amorim, 2007; Marx, 2002; Tosel, 1995).

Contrariamente, para Gorz, no 'não-trabalho' estaria a possibilidade de construção de uma sociedade emancipada do reino das necessidades. A 'não-classe dos não-trabalhadores' teria o potencial revolucionário que fora perdido pelos operários da indústria. A 'não-classe' apontaria para a formação de uma nova cultura de resistência, constituída fora da esfera da produção alienada.

Esboçar-se-ia, assim, uma tendência: a automação liberaria uma parte do operariado tradicional com base no desemprego. Essa liberação seria o indicador da formação de um novo sujeito histórico.

Considerar a 'não-classe' dos 'não-trabalhadores' como sujeito social potencial da abolição do trabalho não decorre de uma opção ideológica ou ética: a opção não está entre abolir o trabalho ou fazer renascer ofícios completos em que cada um possa se realizar. A escolha é entre a abolição libertadora e socialmente controlada do trabalho ou sua abolição opressiva e antissocial (Gorz, 1987, p. 17).

Contudo, qual seria o referencial de Gorz para analisar esse novo sujeito revolucionário que estaria por se formar "fora do trabalho"?

Gorz fundamentou a emancipação do trabalhador como um retorno às atividades do artesão, na qual o trabalho era identificado como uma atividade ainda prazerosa. Com base nisso, passa a descrever a 'nova era' como um inevitável abandono dessa perspectiva. 
Não existiria, assim, alguma possibilidade do trabalhador identificar-se com uma atividade penosa, que impossibilitaria a construção de uma identidade de classe ou de um compromisso de classe. "O trabalho deixa de ser, para ele [o trabalhador], uma atividade ou mesmo uma ocupação principal para se tornar um tempo morto à margem da vida, onde se está 'ocupado' em ganhar algum dinheiro" (Gorz, 1987, p. 89), e por conta disso a luta política só poderia estar no avesso do trabalho.

André Gorz abriu, portanto, com Adeus ao proletariado, o debate sobre o fim das classes sociais, rompendo com a bibliografia marxista que dava sustento a sua análise até então. Gorz, com essa publicação, reformula sua leitura do trabalho, das classes e da luta política amparando-se no processo de requalificação profissional de um conjunto heterogêneo de trabalhadores. ${ }^{3}$

A identidade de classe não poderia mais ser alcançada frente à heterogeneização das categorias profissionais. Contudo, o desenvolvimento dessa mesma racionalidade econômica capitalista, passados alguns anos de reflexão e a permanência do antagonismo de classe inscrito na produção de mercadorias, fez Gorz reformular sua análise para dar início ao debate sobre a imaterialidade do trabalho. 4

As novas formas de exploração do trabalho deslocariam a subordinação do trabalhador a novas representações político-sociais. O capital, ao acionar um tipo de trabalhador adaptado às suas demandas produtivas, teria acabado por criar seu próprio algoz: um tipo de trabalho imaterial. Com isso, um novo segmento nasceria nos escombros do modelo industrialista de produção: os trabalhadores do imaterial.

A desvinculação com as formas tradicionais de produção criaria nesse novo segmento profissional uma negação em relação à produção tipicamente capitalista, uma vez que seu trabalho extravasaria a lógica da exploração do tempo de trabalho criadora de mais-valia. Os conteúdos do novo tipo de trabalho são interpretados como qualificações profissionais anticapitalistas. A pergunta central para o autor seria: como mensurar conteúdos cognitivos? A resposta, para Gorz, é simples: seria impossível!

Abre-se, assim, a perspectiva que evidencia a existência de uma centralidade dinâmica do trabalho imaterial, um tipo de trabalho que seria portador da transformação estrutural da sociedade, da constituição de uma nova forma de produção, entendida, por Gorz, como comunista.

Estabelece-se teoricamente o trabalho imaterial. Um trabalho que é divulgado como coletivo, mas que depende da qualificação individual; que se fundamenta na capacidade de reconhecimento da informação; que não pode ser restringido pelo capital, mas acaba por, novamente, circunscrever-se à lógica de valorização capitalista. 


\section{O debate sobre o trabalho imaterial}

As teses que compõem o debate sobre o trabalho imaterial nos anos 1990 e começo dos anos 2000 parecem não ter continuidade problemática com aquelas do debate sobre a centralidade do trabalho. Parecem, contrariamente, surgir com base em terrenos teóricos distintos. No entanto, esta é a aparência necessária que possibilita, por exemplo, a negação da teoria do valor-trabalho e da teoria das classes sociais e o abandono do trabalho como categoria analítica central, ao se optar por uma análise que passa a indicar a inapreensão, a indeterminação e a imensurabilidade da produção de mercadorias no capitalismo.

Em O imaterial: conhecimento, valor e capital (Gorz, 2005), livro que sintetiza essa discussão, o caráter cognitivo das qualificações profissionais é entendido como momento de extravasamento da lógica do capital. Toda produção teria tendencialmente seu valor reduzido, na medida em que se propaga, em que se torna social. Essa propagação baratearia a mercadoria ao limite, fazendo com que ela mesma perdesse sua forma valor de troca. “(...) Uma autêntica economia do conhecimento corresponderia a um comunismo do saber no qual deixam de ser necessárias as relações monetárias e as de troca" (Gorz, 2005, p. 10).

As formas tradicionais de geração do valor, ou seja, aquelas provindas do trabalho imediato seriam superadas por aquelas dos setores administrativos e de serviço. $\mathrm{O}$ "tempo de trabalho" e o "tempo da vida" são rompidos nessa perspectiva (Gorz, 2005, p. 36). ${ }^{5}$

Existiria, dentro do debate sobre a imaterialidade do trabalho, a ideia geral de que a retomada do controle da produção, mesmo que não esteja associada diretamente à fábrica, não teria relação somente com o trabalho imediato, mas poderia ser constituída a partir do contato técnico de um núcleo de trabalhadores com forças produtivas as mais avançadas. Isto, por extensão, capacitaria este núcleo a se organizar politicamente.

O componente do saber, presente no trabalho industrial e de serviços, teria crescido em importância. Este saber não poderia ser reduzido a saberes técnicos, outrora formalizados. Assim, “o saber da experiência, o discernimento, a capacidade de coordenação, de auto-organização e de comunicação. Em poucas palavras, formas de um saber vivo adquirido no trânsito cotidiano, que pertencem à cultura do cotidiano" (Gorz, 2005, p. 9) formariam uma resistência dentro da lógica de valorização do capital.

As contradições sociais teriam, com isso, fundamentado um tipo de trabalho cujo componente central seria o conhecimento. 6 Nos 'interstícios' da sociedade capitalista teria se formado uma força produtiva cognitiva baseada 
nas experiências cotidianas dos indivíduos. Esta produção imaterial levaria a teoria do valor à excrescência, pois indicaria uma contradição intransponível entre a lógica de universalização dos produtos imateriais e a mercadoria. Com isso, se redimensionaria a forma histórica de valorização do capital. O capital, por seu turno, tentaria restringir o acesso, patentear o conhecimento presente nos produtos comercializados, mas não poderia fazêlo completamente, pois fugiria do seu movimento intrínseco, de extensão ilimitada da exploração do trabalho. Os produtos imateriais romperiam, portanto, com essa lógica expansiva. Dentro do universo da produção imaterial, o valor de troca não faria mais sentido.

Há, nestes termos, um movimento de independicização do trabalho imaterial frente ao processo de acumulação de capital. A imensurabilidade, propriedade característica dos trabalhos imateriais, seria a fonte de um novo processo de valorização. No entanto, ela deveria ser restringida pelo capital. O monopólio do 'capital conhecimento', por exemplo, sintetizaria a contenção dos produtos imateriais. A realidade ilimitada dos produtos cognitivos seria limitada pela contenção, em valor, do processo de acumulação.

Com a diminuição do trabalho imediato, os salários e o valor das mercadorias seriam reduzidos, produzindo uma diminuição dos valores monetários, isto é, da riqueza e dos lucros. O capitalismo cognitivo se apresentaria como momento de "(...) crise do capitalismo em seu sentido mais estrito" (Gorz, 2005, p. 37). Essa leitura acaba por dar base à indicação de uma transição do capitalismo para o comunismo via produção imaterial.

Aqui o trabalho concreto é caracterizado como forma geral do trabalho imaterial. Gorz compreende que o produto do trabalho imaterial não pode ser submetido a uma abstração geral. Deveria ser entendido como um conjunto de utilidades sociais distintas, isto é, como valores de uso distintos. Não teriam mais a função primeira de valorizar o capital.

(...) O trabalho concreto só pode ser transformado naquilo que Marx chamaria de 'trabalho abstrato', fazendo nascer no lugar do operário-produtor o operário-consumidor: quer dizer, o indivíduo social que não produz nada do que consome e não consome nada do que produz; para quem o objetivo essencial do trabalho é ganhar o necessário para comprar as mercadorias produzidas e definidas pela máquina social em seu conjunto (Gorz, 2005, p. 36).

Caracteriza-se, assim, uma contradição em processo. Para que o "capital conhecimento" possa entrar na circulação, ele deve converter-se em capitalmercadoria, deve associar-se às formas tradicionais do capital, já que "ele não é capital, no sentido usual, e não tem como destinação primária a de servir a produção de sobrevalor, nem mesmo de valor, no sentido usual." (Gorz, 2005, p. 54). Não se adequando à norma tradicional de valorização 
do capital e, ao mesmo tempo, desenvolvendo-se como força produtiva central, o "capital conhecimento" se apresentaria como momento de negação dessa lógica.

Assim, o trabalho imaterial abriria novas formas de questionamento político entre os grupos profissionais no momento em que a capacidade de adquirir novas informações, novos conhecimentos técnicos tornaram-se parte integrante do processo de produção.

(...) O trabalho imaterial - aquele que produz os bens imateriais como a informação, os saberes, as ideias, as imagens, as relações e os afetos - tende a tornar-se hegemônico. (...) o trabalho imaterial só pode ser realizado coletivamente, trocando informações, conhecimentos. Por sua vez, estas formas de comunicar, de colaborar e de cooperar produzem o 'comum', que se trate de linguagens, de métodos, de visões, de novos conhecimentos comuns... Toda pessoa que trabalha com a informação ou com o saber - do agricultor que desenvolve as propriedades específicas das sementes ao programador de softwares - utiliza o saber comum transmitido por outros e contribui para produzi-lo (Negri, 2004, p. 44).

A teoria da exploração de Marx é, nesse sentido, reapropriada para a leitura de um ciclo ampliado da produção, não apenas relacionado à produção fabril, mas também à formação de uma rede de trabalhadores imateriais, ou seja, à constituição do general intellect.

A indústria tradicional, como locus de organização da resistência política, cederia seu lugar à grande empresa, uma sociedade-fábrica, isto é, produção/consumo/distribuição tornar-se-iam uma única e mesma coisa que se sintetiza na produção imaterial.

Essa abrangência da produção imaterial seria radicalizada ao universalizar a exploração da subjetividade do trabalhador, fazendo reproduzir a 'subsunção' real de sua condição social. Todavia, tanto na interpretação de Gorz quanto na de Negri, vemos que a apropriação do conceito de trabalho imaterial concentra-se na figura do trabalhador isolado.

Em síntese, a mudança das formas de exploração do trabalho ocasionou a recomposição do conteúdo das qualificações necessárias às formas de produção. Contudo, esses conteúdos que teriam gerado uma subjetividade específica acabaram por capacitar os 'trabalhadores do imaterial' como sujeitos políticos de uma luta anticapitalista.

No entanto, o tempo liberado não qualifica o desenvolvimento do indivíduo social, pois esse tempo é negativamente liberado pela forma do desemprego, da precarização, do subemprego, do banco de horas etc., etc.

A hipótese de Marx da supressão do trabalho vivo e do aumento do trabalho passado nunca foi tão pertinente. No entanto, "não seria o caso de situar (também) no mesmo espaço, a apropriação pelo capital das forças 
intelectuais"? Mas, como considerá-la sob a ótica de que a "missão histórica do capital é de depreciar o valor de troca da força de trabalho, aumentando, assim, a força produtiva e fazendo do desenvolvimento do indivíduo social o novo alvo imanente da produção"? (Tosel, 1995, p. 212).

A dinâmica capitalista, como regulamentação da produção, passa a responder também pelo controle das capacidades cognitivas no trabalho, no sentido em que necessita de indivíduos que estejam aptos a agir e a tomar decisões - mesmo que dentro de padrões estabelecidos. "É neste contexto que deve ser recolocado o problema da medida do trabalho como momento da constituição do trabalho abstrato partindo das atividades intelectuais concretas" (Vincent, 1993, p. 124), particularmente, no que se refere à formação profissional do trabalhador.

As novas formas de recomposição do trabalho, baseadas na incorporação de conhecimentos técnicos, passam a ser um problema para as análises sociológicas sobre o tema. Entender os limites dessa incorporação, na medida em que ela deve estar articulada a uma lógica de conjunto que tende sempre a impedir a autonomização da classe trabalhadora, frente às imposições econômicas e políticas utilizadas pelo capital, são fundamentais para compreender as diferenças objetivas entre trabalhos de tipo material e imaterial.

A diferenciação, portanto, entre material e imaterial torna-se importante não para apontar os limites do capital como relação social hegemônica no capitalismo. As diferenças entre esses tipos de trabalho são importantes, portanto, na medida em que informam como os processos de trabalho utilizam a incorporação de elementos cognitivos com o objetivo de ampliar a produtividade do trabalho.

\section{Trabalho, classe social e luta política}

Os debates sobre a centralidade do trabalho e sobre o trabalho imaterial baseiam-se em uma compreensão reduzida do trabalho, da formação política da classe trabalhadora e das possibilidades de sua luta política. Primeiramente, o trabalhador é vinculado diretamente ao seu posto de trabalho; suas qualificações técnicas informam, assim, as possibilidades de sua prática e consciência políticas como se não existissem práticas políticas para além do trabalho. A classe trabalhadora é definida como uma extensão de suas atribuições técnicas. Há, portanto, uma correspondência indevida entre as formas de apropriação concreta dos saberes empíricos e das potencialidades políticas da classe trabalhadora. Em segundo lugar, e mais especificamente dentro das teorias do trabalho imaterial, a liberação do tempo de trabalho necessário à produção de mercadorias é apresentada como último momento 
das relações sociais capitalistas. A impossibilidade de mensurar os conteúdos dos trabalhos imateriais implicaria, mecanicamente, o fim anunciado do modo de produção capitalista.

Parece-me central destacar que o capital nas últimas quatro décadas aprofundou a lógica de exploração do trabalho. Às técnicas de produção taylor-fordista foram somadas novas formas de persuasão que, articuladas, informam a ideia de que o trabalhador é um parceiro e, como tal, deveria incorporar o 'espírito da empresa capitalista'. A 'subjetividade' do trabalhador é, assim, reclamada pelo capital e colocada a seu serviço.

O capital, dessa forma, aprendeu a controlar as formas de trabalho cognitivo. Aprofundou sua dominação política e econômica na produção quando passou a, dentro de limites preestabelecidos por ele mesmo, utilizar mais adequadamente as capacidades intelectuais do trabalhador. Nestes termos, a perspectiva de liberação do tempo como tempo livre, ou seja, aquele que poderia ser controlado pelo coletivo de trabalhadores organizados, só pode se realizar em uma sociedade de transição socialista, na qual as antigas relações de produção capitalistas vão aos poucos sendo substituídas por relações de produção comunistas.

Nestes termos, a mudança de direção rumo ao comunismo só pode ser caracterizada depois de constituída uma dominação política, isto é, não seria possível a constituição de um tempo livre, sem que toda a sociedade estivesse empenhada ativamente no exercício desse tempo. A liberação do tempo sem essa base material torna-se negativa para a classe trabalhadora na medida em que esse tempo liberado se efetiva na forma do desemprego.

Portanto, o indivíduo social pensado por Marx nos Grundrisse só se revelaria coerente em uma sociedade na qual a direção política já fosse controlada por uma direção de trabalhadores associados em partido político. Esse indivíduo social, representante de um intelecto geral, é fruto da revolução e superação dos meios de produção dominados pelo capital (Marx, 2002, p. 228) e, desse modo, não pode ser associado, como indicam as teses sobre o trabalho imaterial, a práticas políticas constitutivas da lógica burguesa.

Não há, no entanto, para a bibliografia que articula o trabalho imaterial à luta anticapitalista, a necessidade de constituição de uma força social que leve a cabo a tomada do Estado e a direção da economia para a transformação processual das relações sociais capitalistas em relações de produção comunistas. Essa tarefa é indicada como campo de possibilidades aberto pela própria produção imaterial.

Se optássemos por essa perspectiva, concordaríamos com uma análise determinista que evoca as forças produtivas como elemento central de toda mudança política estrutural. A luta política de classes seria, assim, apenas uma consequência do desenvolvimento das forças produtivas em presença. Mas como seria possível indicar tais forças produtivas como elementos 
impulsionadores de reivindicações e práticas políticas anticapitalistas se são elas, em seu conjunto, cristalizações de relações sociais de tipo capitalista?

Nesse sentido, não me parece, com base na leitura dos Grundrisse (2002) e de $O$ capital (1998), possível apontar para uma ruptura como essa. As formas de exploração do trabalho continuam sendo as mesmas e não há uma nova forma de organização da produção que altere, por conta da inserção de novas tecnologias ou de tipos de trabalho (imateriais ou não), o processo de constante ampliação da produtividade do trabalho.

O desenvolvimento das forças produtivas se apresenta como uma das características centrais dessa ampliação. Exatamente por conta disso não é possível descrever uma alteração estrutural das formas de obtenção do lucro motivadas pelo desenvolvimento das forças produtivas. É bom que se frise não há nada de neutro no desenvolvimento dessas forças. Elas têm como objetivo final atender às demandas do processo de valorização. Nesse sentido, toda a ciência e tecnologia introduzidas no universo dos processos de trabalho cumprem o papel não apenas 'econômico' de valorização do capital, mas também político de ampliação do controle dos coletivos de trabalho.

Nesse sentido, as leituras que apontam para a constituição de uma sociedade pós-industrial ou pós-materialista, ou mesmo uma sociedade de serviços, partem da crítica de uma concepção de trabalho e de classe trabalhadora particular, difundida, sobretudo, sob influência do partido comunista soviético. Essa concepção de trabalho, que se desenvolve até a década de 1970, tem como característica central a indicação de que o trabalho imediato-industrial é o meio pelo qual toda luta política deve ser constituída e, por conseguinte, que a classe operária teria uma 'missão histórica': ser o sujeito da revolução socialista.

As teses que compõem a teoria dos novos movimentos sociais, das sociedades pós-industriais ou mesmo das sociedades pós-materialistas, por exemplo, se constituem em resposta a essa leitura de sujeito e de luta política. Seu objetivo foi, portanto, o de ampliar as formas de participação dos indivíduos ou grupos de indivíduos na cena política a outras esferas da sociedade.

Não obstante, creio que apesar de hegemônica no marxismo, essa leitura restrita e dogmática de um operariado como portador de uma 'missão histórica' revolucionária é equivocada. Há em outras tendências, dentro do marxismo mesmo, críticas às ideias de sujeito e de classe operária como portadora, por essência, da revolução socialista.

A bibliografia que se articula em torno do rechaço da teoria das classes e da teoria do valor-trabalho de Marx responde, assim, à parte equivocada das análises sobre as classes sociais e sobre a possibilidade de construção de forças sociais dentro e fora das indústrias. Ao ter um ponto de partida restrito, tendem a diagnosticar as possibilidades de intervenção política em 
direta oposição a ele. Se tais teses, críticas às concepções de Marx, partem de um falso problema, acabam por construir, em oposição, falsas respostas.

Portanto, creio que parte da bibliografia sobre o tema valeu-se de parâmetros físicos para compreender o que seria material ou não material na produção e no trabalho. O debate sobre o trabalho imaterial é constituído, assim, sob a rubrica inversa a essa compreensão. Reproduz-se uma oposição teoricamente ineficaz e não dialética entre material e imaterial como eixo explicativo de todo o debate nos anos 1980, 1990 e 2000. Uma oposição que parece, de um lado, estar presente em dicotomias enrijecidas, como as de trabalho produtivo e improdutivo, de trabalho intelectual e manual, de classe operária e classe trabalhadora e, de outro, que estão expressas nos termos do trabalho cognitivo e trabalho manual, da sociedade do conhecimento e sociedade industrial, do capital imaterial e capital material.

Nunca é demais destacar que a característica central da produção capitalista é qualificada pela forma como ela é organizada e não pela matéria física ou abstrata que é utilizada na produção de mercadorias. Não importa, dessa maneira, se consideramos a produção de uma mercadoria conhecimento ou de uma mercadoria máquina. Pelo contrário, o mais relevante seria analisar como, em que condições, em que encontro de relações sociais o conhecimento e a máquina foram produzidos.

Em termos gerais, ambos podem ter sido produzidos na forma de uma mercadoria capitalista: redução do tempo global de produção com aumento de produtividade, gerando uma diferença para cima, entre o capital inicial e o final, informada pelo pagamento de um salário que não expressa o tempo total gasto na produção. Portanto, indicar que a qualificação profissional do trabalhador, a matéria-prima trabalhada e os recursos utilizados informam e constituem as relações sociais que estruturam o processo de trabalho não impõe a designação de uma materialidade que determina o conjunto das relações sociais.

Volto à questão das forças produtivas. Não há sentido afirmar que a estrutura social pode ou será transformada com o simples desenvolvimento das forças produtivas envolvidas no processo de produção de mercadorias, posto que essas forças produtivas são expressões de relações sociais de produção cristalizadas. ${ }^{7}$ A materialidade é dada, então, pelo conjunto de relações sociais estabelecidas e não pela fisicidade dos elementos ativos em um processo de trabalho.

Falar em materialismo não é simplesmente indicar o caráter tangível das coisas, é muito mais que isso, trata-se de reconhecer as relações efetivas que constituem nossa existência sob um determinado conjunto de relações sociais.

A diferenciação, portanto, entre material e imaterial não se relaciona, nestes termos, ao valor de troca, ao trabalho abstrato, mas sim ao valor de 
uso, ao trabalho concreto. Portanto, a diferenciação entre a materialidade e a imaterialidade do trabalho só faz sentido quanto ao conteúdo do trabalho e não quanto à produção do valor de troca.

Material ou imaterial, a valorização do capital tem fundamento na relação de troca de mercadorias, isto é, em sua forma e não no conteúdo do trabalho empregado. Nesse sentido, não há diferença conceitual entre a produção material ou imaterial. A produção de mais valor não é caracterizada pela relação de transformação física dos objetos trabalhados.

A teoria de Marx evidenciou um conjunto particular de relações sociais que tem por característica central a produção de mercadorias sob um objetivo específico: produzir um número maior de mercadorias, em um tempo cada vez mais reduzido. O valor-trabalho deve, então, ser considerado como um desdobramento das relações sociais que engendram a produção capitalista. A discussão sobre a materialidade e a imaterialidade do trabalho pode ser, então, relacionada muito mais à especificidade da produção capitalista, ou seja, ao objetivo de valorização do capital baseado na ampliação das mercadorias produzidas. Isto é, quanto maior for a produção (em um tempo menor), maior será a mais-valia relativa constitutiva do conjunto de mercadorias. As relações sociais que dão base e garantem essa empreitada sequer se valem da natureza física das coisas.

Podemos observar, com isso, que Marx, em O capital, define valor de troca como a expressão fenomênica do valor que é agregado à mercadoria com base na exploração do trabalho; no tempo médio de trabalho socialmente necessário à produção da mercadoria. Assim, a medida do valor para Marx é o tempo de trabalho despendido na produção, é a utilização da força de trabalho na produção medida em unidades de tempo, sendo que esse valor é fruto de necessidades sociais, sejam elas originadas, é bom que se frise, do estômago ou da fantasia (Marx, 1998, p. 45).

Marx desenvolve a teoria do valor-trabalho como uma teoria da exploração do trabalho. Fundamenta, dessa forma, uma análise social que elege a produção de mercadorias (físicas ou não) como seu objeto científico central e o trabalho abstrato como elemento decisivo para a valorização do capital.

A constituição do valor de troca e, posteriormente, do dinheiro como equivalente geral e mercadoria específica são os elementos que constituem a base do raciocínio de Marx sobre o processo de exploração do trabalho, com o objetivo de ampliação da mais-valia relativa com base na redução do tempo de trabalho necessário e aumento da produtividade. O trabalho abstrato é demarcado, assim, como um trabalho em geral, que expressa quantidades diferentes de valores de troca das mercadorias, tornando-as socialmente intercambiáveis. O trabalho abstrato constitui-se, portanto, como um regulador das trocas de mercadorias distintas, isto é, com diferentes quantidades de tempo médio socialmente necessário para a sua produção. 
Se a relação social central nas sociedades capitalistas fundamenta-se pela produção de mercadorias e essas mercadorias se constituem pela relação de exploração baseada na extração de mais trabalho, produtivo é todo aquele trabalho ou coletivo de trabalho que esteja subordinado a essa relação, que tem como objetivo reproduzir as relações sociais que dão base à produção de valores de troca. É possível, ademais, admitirmos que o núcleo de extração de mais trabalho esteja ainda hoje vinculado à produção fabril. No entanto, isso não permite concluir que a produção de coisas físicas seja a única a produzir mais-valia.

Concluo esses comentários enfatizando que a materialidade do trabalho e da produção não está vinculada ao conteúdo do trabalho ou das qualificações profissionais que o trabalhador adquire e utiliza nos processos de trabalho. A materialidade está vinculada ao conjunto de relações sociais que informam uma prática social que passa pela organização do processo de produção como elemento de constituição de um modo de vida.

A organização da produção é, portanto, a cristalização de relações sociais e como tal não pode ser pensada com base no caráter físico das matérias envolvidas. A imaterialidade do produto ou da qualificação profissional que é utilizada tem a ver apenas com o trabalho concreto, com a utilidade do produto, mas nunca com o trabalho abstrato, ou seja, não tem a ver com a formação de mais-valor. Nesse sentido, a mercadoria-informação deve ser considerada dentro do universo da produção no sentido estrito, já que está inserida na mesma lógica que informa a produção de mercadorias da indústria chamada tradicional.

\section{Notas}

1 Professor adjunto de Sociologia da Universidade Federal de São Paulo (Unifesp), Guarulhos, Brasil. Doutor em Ciências Sociais pela Universidade Estadual de Campinas (Unicamp). Pós-doutorado na École des Hautes Études en Sciences Sociales (EHESS) e na Universidade Estadual de Campinas (Unicamp). <henriqueamorim@hotmail.com> Correspondência: Universidade Federal de São Paulo (Unifesp), Estrada do Caminho Velho, 333, CEP 07252-312, Bairro dos Pimentas, Guarulhos, São Paulo, Brasil.

2 Sobre essa questão, ver Friedmann e Naville (1964) e Friedmann (1972).

3 Sobre a ruptura de Gorz com as teses do paradigma produtivo, ver Nicolas-Le-Strat (1996) e Artous (2003).

4 Gorz (1987; 1983; 1988; 2005), Lazzarato (1992, 1993; e 1996), Negri (1992; 1993; 1996; 2004). 
5 Na esteira dessa perspectiva, Habermas, em Teoria de la Accion Comunicativa (1987), desenvolve a diferenciação entre sistema e mundo da vida.

6 Lembremos, rapidamente, da tese de Gorz desenvolvida em Adeus ao proletariado (1987), segundo a qual a sociedade capitalista estaria fundada em uma dualização: sociedade heterônoma versus sociedade autônoma.

7 Para Bihr (2001, p. 57, tomo I), “(...) As forças produtivas constituem em conjunto o conteúdo ao mesmo tempo material e social das relações de produção."

\section{Referências}

AMORIM, Henrique. Valor-trabalho e trabalho imaterial nas ciências sociais contemporâneas. Caderno $C R H$, Salvador, v. 23, n. 58, abr. 2010, p. 191-202.

Trabalho imaterial, classe social e qualificações profissionais. In: SOUSA, José dos Santos; ARAÚJO, Renan (Org.). Trabalho, Educação e Sociabilidade. Maringá: Práxis, 2010. p. 159-172.

A relação entre novas tecnologias da informação e a teoria do valor-trabalho. Revista do Instituto Humanitas Unisinos (Notícias do Dia), São Leopoldo, 2009. Disponível em: www.ihu.unisinos.br/index. php?option $=$ com_noticias \&Itemid $=18 \&$ task $=$ detalhe\&id $=27473$. Acesso em: 5 maio 2010 .

Trabalho imaterial: Marx e o debate contemporâneo. São Paulo: Annablume, 2009.

Trabalho imaterial, forças produtivas e transição nos Grundrisse de Karl Marx. Crítica Marxista, Campinas, n. 25, 2007, p. 9-30.

Teoria social e reducionismo analitico: para uma crítica ao debate sobre a centralidade do trabalho. Caxias do Sul: EDUCS, 2006.

ARTOUS, Antoine. Travail et Émancipation Sociales: Marx et le Travail. Paris: Syllepse, 2003.
BIHR, Alain. La Reproduction du Capital. Prolégomènes à une théorie générale du capitalisme. Paris: Editions Page Deux, 2001.

FRIEDMANN, G.; NAVILLE, Pierre. Traité de Sociologie du Travail. Paris: Librairie Armand Colin, 1964, v. I e II.

FRIEDMANN, Georges. O trabalho em migalhas. São Paulo: Perspectiva, 1972.

GORZ, André. Estratégia operária e neocapitalismo. Rio de Janeiro: Zahar, 1968.

Adeus ao proletariado: para além do socialismo. Rio de Janeiro: Forense, 1987. Métamorphoses du Travail. Quête du Sens: critique de la raison economique. Paris: Galilée, 1988.

O imaterial: conhecimento, valor e capital. São Paulo: Annablume, 2005.

HABERMAS, Jünger. Teoria de la Accion Comunicativa. Madrid: Taurus, 1987.

LAZZARATO, Maurizio. Le Concept de Travail Immatériel: la grande entreprise. Futur Antérieur, Paris, n. 10, 1992/2, p. 54-61.

Le cycle de la Production Immatérielle. Futur Antérieur, Paris, n. 16, 1993, p. 111-120. 
. Le 'travail': un nouveau débat pour de veilles alternatives. Futur Antérieur, Paris, 1996/2, n. 35-36.

MARX, Karl. O capital. São Paulo: Nova Cultural, 1998.

Elementos Fundamentales para la Crítica de la Economia Política (Grundrisse/Borrador). Buenos Aires: Siglo Veintiuno Argentina Editores, 2002.

NEGRI, Toni; VINCENT, Jean-Marie. Paradoxes autour du travail. Futur Antérieur, Paris, $1992 / 2$, n. 10, p. 5-8.

NEGRI, Toni. République constituante. Futur Antérieur, Paris, n. 15, 1993/1, p. 71-80.

Marx et le travail: le chemin de la désutopie. Futur Antérieur, Paris, n. 35-36, 1996/2, p. 189-207.
. De l'Avenir de la Democracie (Débat avec Olivier Mongin). Alternatives Internationales, Paris, 2004, n. 18, p. 44-47.

NICOLAS-LE-STRAT, Pascal. Travail et constitution du sens à propos d'André Gorz. Futur Antérieur, Paris, n. 35-36, 1996/2, p. 101-109.

OFFE, Claus. Trabalho e sociedade. v. I. Rio de Janeiro: Tempo Brasileiro, 1989.

TOSEL, André. Centralité et non-centralité du travail ou la passion des hommes superflus. In: BIDET, Jaques ; TEXIER, Jaques. La Crise du Travail. Paris: PUF, 1995. p. 209-218.

VINCENT, Jean-Marie. Les Automatismes Sociaux et le 'général intellect'. Futur Antérieur, Paris, n. 16, 1993, p. 121-130.

Recebido em 21/06/2010

Aprovado em 13/09/2010 